
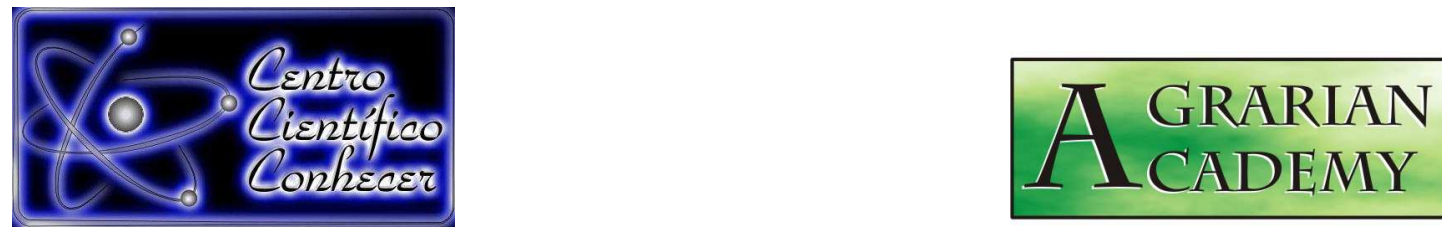

\title{
DIÁSPOROS DE Cereus jamacaru P. DC. SUBMETIDAS AO TESTE DE CONDUTIVIDADE ELÉTRICA
}

\author{
Rafael Mateus Alves ${ }^{1}$, Monalisa Alves Diniz da Silva Camargo Pinto ${ }^{2}$, Joyce Naiara \\ da Silva ${ }^{1}$, Ana Karlla Penna Rocha ${ }^{1}$, Elania Freire da Silva ${ }^{1}$. \\ 1 Graduandos do Curso de Bacharelado Agronomia da Universidade Federal \\ Rural de Pernambuco/ Unidade Acadêmica de Serra Talhada (UFRPE/UAST) \\ (rafaelalvesmateus@gmail.com) - Serra Talhada - PE - Brasil \\ 2 Profa Dra Associado I do Departamento de Agronomia da Universidade Federal \\ Rural de Pernambuco/ Unidade Acadêmica de Serra Talhada (UFRPE/UAST) \\ Serra Talhada - PE - Brasil \\ Recebido em: 30/11/2017 - Aprovado em: 15/12/2017 - Publicado em: \\ 31/12/2017 \\ DOI: 10.18677/Agrarian Academy 2017b11
}

\begin{abstract}
RESUMO
Objetivou-se averiguar a aplicabilidade do teste de condutividade elétrica na determinação do vigor de diásporos de Cereus jamacaru. Empregou-se dois lotes de diáporos, de acordo com a safra (2015 e 2016) e onze períodos de embebição: 15, 30, 60, 120, 150 minutos e 4,6,8,10, 12 e 24 horas, com um delineamento inteiramente ao acaso disposto em arranjo fatorial $2 \times 10$, para cada volume água (25 e $50 \mathrm{~mL}$ ). Os lotes foram caracterizados quanto ao grau de umidade, protrusão da raiz primária (germinação), porcentagem de protrusão da raiz primária, índice de velocidade de protrusão da raiz primária, tempo médio de protrusão da raiz primária. Os diásporos colhidos no ano de 2016 apresentavam-se mais deteriorados em relação aos diásporos provenientes do ano de 2015, pois germinaram menos e lixiviaram mais, independentemente do volume de água utilizada. Os diásporos de mandacaru quando imersos em $25 \mathrm{~mL}$ de água por 30 minutos, apresentaram diferenças quanto à lixiviação de exsudatos entre as safras de 2015 e 2016; já para o volume de imersão de $50 \mathrm{~mL}$ a diferença entre as duas safras só foi observada a partir dos 120 minutos de embebição.
\end{abstract}

PALAVRAS-CHAVE: deterioração, lixiviação, potencial fisiológico. 


\title{
DIAMONDS OF Cereus jamacaru P. DC. SUBMITTED TO THE ELECTRICAL CONDUCTIVITY TEST
}

\begin{abstract}
The objective of this study was to investigate the applicability of the electrical conductivity test in determining the vigor of cereus jamacaru diaspores. Two batches of diaporos were used, according to the harvest (2015 and 2016) and eleven soaking periods: 15, 30, 60, 120, 150 minutes and 4,6,8,10, 12 and 24 hours), with a completely randomized design arranged in a $2 \times 10$ factorial arrangement, for each water volume (25 and $50 \mathrm{~mL}$ ). The lots were characterized for moisture degree, primary root protrusion (germination), primary root protrusion percentage, primary root protrusion velocity index, mean primary root protrusion time. The diaspores harvested in the year 2016 were more deteriorated in relation to the diaspores from the year 2015, as they germinated less and leached more, regardless of the amount of water used. The mandacaru diaspores when immersed in $25 \mathrm{~mL}$ of water for 30 minutes showed differences in the leaching of exudates between the harvests of 2015 and 2016; already for the volume of immersion of $50 \mathrm{~mL}$ the difference between the two harvests was only observed from the 120 minutes of imbibition.
\end{abstract}

KEYWORDS: deterioration, leaching, physiological potential

\section{INTRODUÇÃO}

Para se adaptar melhor às condições de alta luminosidade, alta temperatura e déficit hídrico, características presentes no bioma Caatinga do semiárido nordestino, algumas plantas necessitam de mecanismos para sobreviver e perpetuar seu genótipo. As espécies da família Cactaceae são reconhecidas por sua eficiência do uso da água, tal característica é responsável pelo metabolismo ácido das crassuláceas (SANTOS et al., 2013).

O Cereus jamacaru P. DC., popularmente conhecido como mandacaru, é uma espécie arbórea de origem brasileira frequentemente encontrada no Semiárido nordestino. Possui características benéficas como a utilização para fins medicinais e cosmecêuticos, alimentação de animais, decoração e ornamentação, indústria alimentícia, nidificação por vespas, manutenção da zona apícola da região e ajuda na conservação da biodiversidade da Caatinga (LEAL SALES et al., 2014; LUCENA et al., 2015; SANTOS ; SOUZA, 2016).

Os estudos sobre os benefícios medicinais do mandacaru são poucos e necessitam de mais pesquisas, porém os sertanejos adeptos da medicina popular utilizam a casca e caule para tratar problemas renais, digestivos e hepáticos além de funcionar como laxante, cicatrizante e anti helmíntico (MESSIAS et al., 2010). Por sua vez as extrações desordenadas do $C$. jamacaru P. DC. para fins ornamentais e para implantação de pastagens, o mesmo enfrenta alto potencial de extinção (SANTOS ; SOUZA, 2016). Para contornar esta situação, o extrativismo predatório deve ser evitado e as vegetações nativas conservadas e propagadas.

A propagação assexuada, ou seja, via cladódios, é uma forma viável e rápida de obter plantas em um curto intervalo de tempo. Este modo é mais utilizado para produção comercial de mudas. A propagação via diásporos, além de favorecer a 
produção comercial de mudas, é indicada para programas de melhoramento vegetal no qual se deseja a multiplicação e conservação de genótipos de interesse. Para isto, torna-se imprescindível o emprego de diásporos de qualidade superior. Um dos fatores preponderantes é o vigor, ou seja, para ter diásporos de alta qualidade fisiológica estes devem ter alta germinação em laboratório, emergência rápida no campo tolerando possíveis mudanças climáticas e após armazenadas não perder estas características (CARVALHO et al., 2014).

Um dos testes mais utilizados para verificação de vigor de diásporos é o da condutividade elétrica, por ser rápido, simples e prático (PEREIRA et al., 2015). Os diásporos com um sistema de membranas bem estruturado e integro, liberam menor quantidade de exsudatos. Portanto, contém maior reserva de energia para a emergência e estabelecimento de plântulas vigorosas. Com base no exposto, a pesquisa visou a avaliação do vigor de diásporos de Cereus jamacaru P. DC., por meio da lixiviação de exsudatos.

\section{MATERIAL E MÉTODOS}

A pesquisa foi conduzida na Universidade Federal Rural de Pernambuco/Unidade Acadêmica de Serra Talhada (UFRPE/UAST), nos meses de setembro a outubro de 2017. Os frutos de Cereus jamacaru P. DC. foram coletados de matrizes da cidade de Serra Talhada-PE, entre os anos de 2015 e 2016. A região correspondente ao município de Serra Talhada, tem o clima predominante de semiárido quente, altitude de $444 \mathrm{~m}$ a $7^{\circ} 59^{\prime} 9^{\prime \prime S}$ e $38^{\circ} 17^{\prime} 45^{\prime \prime} \mathrm{W}$, com precipitação média anual entre 380 e 760 mm, segundo a classificação climática de KöppenGeiger. Após a extração manual dos diásporos, os mesmos foram secos, beneficiados, e posteriormente armazenados em embalagens de vidro em condições naturais, até o início das análises. Para a caracterização fisiológica, os diásporos foram submetidos as seguintes avaliações:

Grau de umidade - determinado pelo método de estufa a $105 \pm 3 \stackrel{\circ}{\circ}$ por 24 horas (BRASIL, 2009), utilizando quatro repetições de cem diásporos para cada lote, sendo os resultados expressos em porcentagem de umidade calculada na base do peso úmido.

Germinação - os diásporos foram distribuídos sobre duas folhas de papel mata-borrão, e posteriormente umedecidas com água destilada na proporção de 2,5 vezes o peso do papel seco e acondicionadas em caixas acrílicas transparentes (gerbox) com dimensões de $11 \times 11 \times 3 \mathrm{~cm}$. As caixas foram colocadas no interior de sacos plásticos e mantidas em sala climatizada sob iluminação constante durante 10 dias. A temperatura e a umidade relativa do ar máxima e mínima da sala foram monitoradas diariamente por meio de um termo higrômetro digital, cujas médias registradas foram de $22,14^{\circ} \mathrm{C}$ e $45,20 \%$, respectivamente. Ao final do teste, quantificou-se os diásporos germinados em relação a protrusão da raiz $(2 \mathrm{~mm})$. Adotou-se o delineamento inteiramente ao acaso com 10 repetições de 50 diásporos por lote.

Índice de Velocidade de Protrusão da Raiz Primária (IVPRP) - foi obtido por meio de contagem diária do número de diásporos que emitiram a raiz primária a partir do $5^{\circ}$ dia após a semeadura, finalizando-se no $10^{\circ}$ dia, segundo Maguire (1962). 
Tempo médio de protrusão da raiz primária (TMPRP) - realizou-se simultaneamente com o teste de germinação, sendo os resultados expressos em dias, os dados foram calculados por meio da fórmula descrita por Labouriau e Valadares (1976).

Condutividade elétrica - Executou-se dois experimentos de condutividade elétrica, sendo que cada um correspondeu a um volume de água destilada distinto (25 e $50 \mathrm{~mL}$ ), empregando delineamento inteiramente ao acaso disposto em arranjo fatorial 2 x 10 (dois lotes: 2015 e 2016 e 11 períodos de embebição: 15, 30, 60, 120 e 150 minutos e 4, 6, 8, 10, 12 e 24 horas), para cada uma das quatro repetições de cada tratamento foram utilizadas 50 diásporos. Inicialmente determinou-se a massa dos diásporos em balança analítica de 0,001 g, e em seguida os mesmos foram colocados para embeber em copos descartáveis com capacidade para $100 \mathrm{~mL}$, contendo 25 e $50 \mathrm{~mL}$ de água destilada, conforme o experimento, em condição ambiental de laboratório à $25 \pm 2{ }^{\circ} \mathrm{C}$. Transcorridos os períodos de embebição, a condutividade elétrica da solução foi mensurada por meio de leituras em um condutivímetro de bancada. A leitura foi realizada gradativamente agitando-se previamente cada recipiente com o intuito de uniformizar os solutos lixiviados. Após a leitura, calculou-se os valores da condutividade elétrica por grama de diásporos,

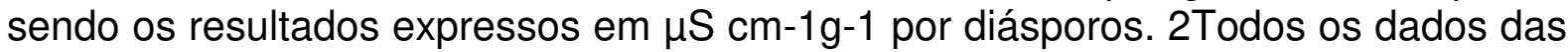
variáveis foram submetidos à análise de variância, e as médias comparadas pelo teste de Tukey ao nível $5 \%$ de probabilidade. As análises estatísticas foram feitas através do software ASSISTAT®, versão 7.7 beta.

\section{RESULTADOS E DISCUSSÃO}

O grau de umidade dos diásporos foi significativamente distinto entre os dois lotes estudados, observou-se que os diásporos coletados no ano de 2015 estavam mais secos em relação aos diásporos do lote de 2016 (Tabela 1), os quais apresentaram maior grau de umidade, o que pode ser consequência de uma maior precipitação no ano de coleta dos diásporos.

TABELA 1- Caracterização de diásporos de mandacaru (Cereus jamacaru P. DC) provenientes de dois anos de colheita, quanto ao grau de umidade (GU), porcentagem de protrusão da raiz primária (PPRP), índice de velocidade de protrusão da raiz primária (IVPRP), tempo médio de protrusão da raiz primária (TMPRP).

\begin{tabular}{lllll}
\hline Lotes & GU (\%) & PPRP (\%) & IVPRP & TMPRP (dias) \\
\hline $\mathbf{2 0 1 5}$ & $9,43 \mathrm{~b}$ & $79,00 \mathrm{a}$ & $5,76 \mathrm{a}$ & $1,46 \mathrm{a}$ \\
$\mathbf{2 0 1 6}$ & $20,66 \mathrm{a}$ & $52,40 \mathrm{~b}$ & $3,48 \mathrm{~b}$ & $1,55 \mathrm{a}$ \\
\hline CV (\%) & 32,66 & 26,58 & 26,55 & 25,45 \\
\hline
\end{tabular}

Médias seguidas pelas mesmas letras, nas colunas, não diferem entre si pelo teste de Tukey a $5 \%$ de probabilidade 
TABELA 2- Resultados da análise de variância da condutividade elétrica $\left(\mu \mathrm{S} . \mathrm{cm}^{-1} \mathrm{~g}^{-1}\right.$ ) de diásporos de mandacaru (Cereus jamacaru P. DC.) em função do ano de coleta e dos períodos de embebição, embebidas em 25 e $50 \mathrm{~mL}$ de água destilada.

\begin{tabular}{|c|c|c|}
\hline Fator de variação & $25 \mathrm{~mL}$ & $50 \mathrm{~mL}$ \\
\hline F1 (lotes) & $78,25^{\star \star}$ & $0,66^{\text {ns }}$ \\
\hline F2 (períodos de embebição) & $146,49^{\star *}$ & $23,66^{* *}$ \\
\hline F1 x F2 & $27,09^{\star *}$ & $5,28^{* *}$ \\
\hline CV (\%) & 19,56 & 24,51 \\
\hline
\end{tabular}

Médias seguidas pelas mesmas letras (maiúsculas nas colunas e minúsculas nas linhas) não diferem entre si pelo teste de Tukey a $5 \%$ de probabilidade.

** significativo ao nível de $1 \%$ de probabilidade; * significativo ao nível de $5 \%$ de probabilidade; ${ }^{\text {ns }}$ não significativo; coeficiente de variação (CV).

A análise dos resultados de lixiviação de exsudatos provenientes dos diásporos de Cereus jamacaru (Tabelas 2, 3 e 4) permitiu verificar que os diásporos colhidos no ano de 2016 apresentavam-se mais deteriorados em relação aos diásporos colhidos no ano de 2015, quando foi utilizado um volume de $25 \mathrm{~mL}$ de água para os diferentes períodos de embebição, já quando utilizou-se $50 \mathrm{~mL}$ de água não houve diferença significativa.

A deterioração mais acentuada nos diásporos colhidos no ano de 2016 pode estar relacionada as condições ambientais. É importante evidenciar que o processo de deterioração dos diásporos armazenados é inevitável, sendo que as sementes já iniciam o armazenamento com uma qualidade inicial, a qual depende de vários fatores, tais como o vigor da planta ascendente, as condições climáticas durante o desenvolvimento do diásporo, o ataque de microrganismos patogênicos, o grau de maturação, a secagem após a extração dos diásporos dentre outros (MARCOS FILHO, 2005).

Avaliando o lote de 2015 para os diferentes períodos de embebição e utilizando $25 \mathrm{~mL}$ de água destilada, pôde-se verificar que os períodos de $15,30,60$, 120, 150 e 240 minutos proporcionaram menores valores de condutividade elétrica, a partir de seis horas a lixiviação de solutos foi aumentando sendo que o período de 24 horas foi o que propiciou maior liberação na quantidade de lixiviados. Para o lote de 2016, os cinco primeiros períodos de embebição ocasionaram menor lixiviação, sendo que o período de 10 horas propiciou maior valor de condutividade. Os resultados obtidos nos dois lotes corroboram com o trabalho de Dalanhol et al. (2014), pois ao avaliarem diásporos de Bowdichia virgilioides Kunth de diferentes cores em diferentes períodos de embebição (12, 24, 36, 48, 60 e 72 horas) em um volume de $25 \mathrm{~mL}$, observaram que a medida que aumentava o tempo de imersão, os valores da CE também aumentavam. 
TABELA 3- Condutividade elétrica $\left(\mu \mathrm{S} . \mathrm{cm}^{-1} \mathrm{~g}^{-1}\right)$ de lotes de diásporos de mandacaru (Cereus jamacaru P. DC.) em diferentes períodos de embebição, imersas em $25 \mathrm{~mL}$ de água destilada.

\begin{tabular}{ccc}
\hline & \multicolumn{3}{c}{ Lotes } \\
\cline { 2 - 3 } Períodos de embebição & $\mathbf{2 0 1 5}$ & $\mathbf{2 0 1 6}$ \\
\hline $\mathbf{1 5}$ minutos & $4,0550 \mathrm{Da}$ & $5,3250 \mathrm{Ea}$ \\
$\mathbf{3 0}$ minutos & $4,9000 \mathrm{Db}$ & $9,2225 \mathrm{DEa}$ \\
$\mathbf{6 0}$ minutos & $5,5125 \mathrm{Db}$ & $10,2950 \mathrm{CDEa}$ \\
$\mathbf{1 2 0}$ minutos & $7,7425 \mathrm{CDa}$ & $9,7075 \mathrm{DEa}$ \\
$\mathbf{1 5 0}$ minutos & $8,4900 \mathrm{CDa}$ & $7,4000 \mathrm{Ea}$ \\
$\mathbf{2 4 0}$ minutos & $7,9225 \mathrm{CDb}$ & $14,77500 \mathrm{BCa}$ \\
$\mathbf{6}$ horas & $11,6650 \mathrm{BCa}$ & $10,2300 \mathrm{CDEa}$ \\
$\mathbf{8}$ horas & $11,1875 \mathrm{BCa}$ & $13,7400 \mathrm{BCDa}$ \\
$\mathbf{1 0}$ horas & $13,9575 \mathrm{Bb}$ & $20,9500 \mathrm{Aa}$ \\
$\mathbf{1 2}$ horas & $13,8450 \mathrm{Ba}$ & $12,9825 \mathrm{BCDa}$ \\
$\mathbf{2 4}$ horas & $20,6500 \mathrm{Aa}$ & $16,0450 \mathrm{ABa}$ \\
\hline $\mathbf{C V}(\%)$ & 19,56 & 24,51
\end{tabular}

Médias seguidas pelas mesmas letras (maiúsculas nas colunas e minúsculas nas linhas) não diferem entre si pelo teste de Tukey a 5\% de probabilidade.

Os diásporos que ficaram embebidos em um volume de $50 \mathrm{~mL}$, apresentaram comportamento semelhante aquelas imersas em $25 \mathrm{~mL}$, pois à medida que aumentou o período de embebição, houve maior lixiviação de exsudatos, sendo que para o lote de 2015 no período de 24 horas a lixiviação foi significativamente superior em relação aos demais períodos; enquanto que para o lote de 2016 o período de embebição de 10 horas propiciou maior lixiviação de exsudatos. Pereira et al., (2015) avaliando diásporos de Piptadenia moniliformis Benth. também constataram maior lixiviação de eletrólitos à medida que o período de imersão aumentava.

TABELA 4- Condutividade elétrica $\left(\mu S . \mathrm{cm}^{-1} \mathrm{~g}^{-1}\right)$ de lotes de diásporos de mandacaru (Cereus jamacaru P. DC.) em diferentes períodos de embebição, imersas em $50 \mathrm{~mL}$ de água destilada.

\begin{tabular}{ccc}
\hline & \multicolumn{2}{c}{ Lotes } \\
\cline { 2 - 3 } Períodos de embebição & $\mathbf{2 0 1 5}$ & $\mathbf{2 0 1 6}$ \\
\hline $\mathbf{1 5}$ minutos & $2,2550 \mathrm{Ea}$ & $1,4800 \mathrm{Da}$ \\
$\mathbf{3 0}$ minutos & $2,2600 \mathrm{Ea}$ & $1,7775 \mathrm{CDa}$ \\
$\mathbf{6 0}$ minutos & $3,1950 \mathrm{DEa}$ & $4,3775 \mathrm{BCa}$ \\
$\mathbf{1 2 0}$ minutos & $3,3050 \mathrm{CDEb}$ & $5,1300 \mathrm{ABa}$ \\
$\mathbf{1 5 0}$ minutos & $6,2750 \mathrm{Ba}$ & $4,1925 \mathrm{BCDb}$ \\
$\mathbf{2 4 0}$ minutos & $6,0375 \mathrm{Ba}$ & $4,3800 \mathrm{BCb}$ \\
$\mathbf{6}$ horas & $4,9500 \mathrm{BCDEb}$ & $7,4550 \mathrm{Aa}$ \\
$\mathbf{8}$ horas & $5,0450 \mathrm{BCDa}$ & $5,2925 \mathrm{ABa}$ \\
$\mathbf{1 0}$ horas & $5,9375 \mathrm{BCa}$ & $5,3925 \mathrm{ABa}$ \\
$\mathbf{1 2}$ horas & $4,4825 \mathrm{BCDEa}$ & $5,0300 \mathrm{ABa}$ \\
$\mathbf{2 4}$ horas & $9,0925 \mathrm{Aa}$ & $6,4200 \mathrm{ABb}$ \\
\hline $\mathbf{C V}$ (\%) & 24,51 & \\
\hline
\end{tabular}

Médias seguidas pelas mesmas letras (maiúsculas nas colunas e minúsculas nas linhas) não diferem entre si pelo teste de Tukey a $5 \%$ de probabilidade. 
Observa-se que quantidades diferentes de água destilada podem interferir na leitura da condutividade elétrica, sendo que menos lixiviados são verificados à medida que ocorre um acréscimo de água corroborando com resultados encontrados para diásporos de Bowdichia virgilioides Kunth (DALANHOL et al., 2014), Coriandrum sativum L. (TORRES et al., 2015) e Moringa oleifera L. (MEDEIROS et al., 2017). Quando avaliado cada tempo de embebição nos volumes de $25 \mathrm{~mL}$ (Tabela 3) e 50 $\mathrm{mL}$ (Tabela 4), observa-se que, de forma geral, não houve diferenças entre os valores de condutividade elétrica dos dois lotes, indicando ausência de alterações significativas na organização do sistema de membranas dos lotes das duas safras. Salienta-se que nem sempre é verificado que a CE está ligada com a diminuição do vigor; assim em diásporos de Albizia hassleri, o teste não foi eficiente na diferenciação dos lotes analisados (GONZALES et al., 2009).

\section{CONCLUSÕES}

Os diásporos de mandacaru quando imersos em $25 \mathrm{~mL}$ de água por 30 minutos, apresentaram diferenças quanto à lixiviação de exsudatos entre as safras de 2015 e 2016; já para o volume de imersão de $50 \mathrm{~mL}$ a diferença entre as duas safras só foi observada a partir dos 120 minutos de embebição.

\section{REFERÊNCIAS}

CARVALHO, E. R.; OLIVEIRA, J. A.; CALDEIRA, C. M. Qualidade fisiológica de sementes de soja convencional e transgênica RR produzidas sob aplicação foliar de manganês. Bragantia, v. 73, n. 3, p. 219-228, 2014. Disponível em: $<$ http://www.scielo.br/pdf/brag/v73n3/aop_brag_0096_pt.pdf>. http://dx.doi.org/10.1590/1678-4499.0096.

BRASIL, Ministério da Agricultura, Pecuária e Abastecimento. Regras para análise de sementes. Brasília-DF, 2009, 399p.

DALANHOL, S. J.; REZENDE, E. H.; ABREU, D. C. A.; NOGUEIRA, A. C. Teste de condutividade elétrica em sementes de Bowdichia virgilioides Kunth. Revista Floresta e Ambiente, Rio de Janeiro-RJ, v. 21, n. 1, p. 69-77, 2014.

GONZALES, J. L. S.; PAULA, R. C. VALERI, S. V. Teste de condutividade elétrica em

sementes de Albizia hassleri (Chod.) Burkart (Fabaceae-Mimosoideae). Revista Árvore, Viçosa-MG, v. 33, n. 4, p. 625-634, 2009.

LABOURIAU, L. G.; VALADARES, M. E. B. On the germination of seeds Calotropis procera (Ait.) Ait. f. Anais da Academia Brasileira de Ciências, Rio de Janeiro-RJ, v. 48, n. 2, p. 263-284, 1976.

LEAL SALES, M. S.; MARTINS, L. V.; SOUZA, I.; MEIRELLES DE DEUS, M. S.; PERON, A. P. Cereus Jamacaru de Candolle (Cactaceae), O Mandacaru do Nordeste Brasileiro. UEPG Ciências Biológicas e Saúde, v. 20, n. 2, p. 135-142, 2014. 
<http://177.101.17.124/index.php/biologica/article/view/6353/4834>.

doi: 10.5212/Publ.Biologicas.v.20i2.0006.

LUCENA, C. M.; RIBEIRO, J. E. S.; NUNES, E. N.; MEIADO, M. V.; QUIRINO, Z. G. M.; CASA, A.; LUCENA, R. F. P. Distribuição local de Cereus jamacaru dc. Subsp. Jamacaru e Pilosocereus pachycladus F. Ritter subsp. Pernambucoensis (f. Ritter) zappi (Cactaceae) e sua relação com uma comunidade rural no município do Congo, Paraíba. Gaia Scientia, v. 9, n. 2, p. 97-103, 2015. Disponível em: < http://periodicos.ufpb.br/index.php/gaia/article/view/24499/13393>.

doi: http://dx.doi.org/10.21707/gs.v9i2.24499.0

MARCOS FILHO, J. Fisiologia de sementes de plantas cultivadas. Piracicaba: Fealq, 2005. 496 p.

MEDEIROS M. L. S.; PÁdUA G. V. G.; PEREIRA M. D. Adaptação do teste de condutividade elétrica para sementes de Moringa oleífera. Pesquisa Florestal Brasileira, v. 37, n. 91, p. 269-275, 2017. Disponível em <http://pfb.cnpf.embrapa.br/pfb/index.php/pfb/article/view/1384/586>

doi: 10.4336/2017.pfb.37.91.1384.

MAGUIRE, J. D. Speed of germination-aid in and evaluation for seedling emergence and vigour. Crop Science, Madison, v. 2, n. 1, p. 176-177, 1962.

MESSIAS, J. B.; CARACIOLO, M. C. M.; OLIVEIRA, I. M.; MONTARROYOS, U. R.; BASTOS, I. V. G. A.; GUERRA, M. O.; SOUZA, I. A. Avaliação dos parâmetros hematológicos e bioquímicos de ratas no segundo terço da gestação submetidas à ação do extrato metanólico de Cereus jamacaru DC., Cactaceae. Revista Brasileira de Farmacognosia, v. 20, n. 4, p. 478-483, 2010. Disponível em: < http://www.scielo.br/scielo.php?script=sci_arttext\&pid=S0102-

695X2010000400003>. doi: http://dx.doi.org/10.1590/S0102-695X2010000400003.

PEREIRA. K. T. O.; AQUINO G. S. M.; ALVES T.R.C.; BENEDITO. C.P.; TORRES S. B. Teste de condutividade elétrica em sementes de Piptadenia moniliformis Benth. Journal of Seed Science. v.37 n.4. 2015. Disponível em:http://www.scielo.br/scielo.php?script=sci_arttext\&pid=S23171537201500040019 9\&lng=pt\&nrm=iso\&tlng=pt. Doi: http://dx.doi.org/10.1590/2317-1545v37n4152357.

SANTOS, D. C.; SILVA, M. C.; DUBEUX JUNIOR, J. C. B.; LIRA, M. A.; SILVA, R. M. Estratégias para uso de cactáceas em zonas semiáridas: novas cultivares e uso sustentável das espécies nativas. Revista Científica de Produção Animal, v. 15, n. 2, p. 111-121, 2013.2 Disponível em: <http://revistas.ufpi.br/index.php/rcpa/article/viewFile/2166/1502>. doi: http://dx.doi.org/10.15528/2176-4158/rcpa.v15n2p111-121.

SANTOS, J. I. G.; SOUZA, D. D. O mandacaru como fonte alimentar para caprinos no período de seca no semiárido. Caderno Meio Ambiente e Sustentabilidade, v. 
9, n. 5, $\quad$ p. $5-14, \quad 2016 . \quad$ Disponível em: <https://www.uninter.com/cadernosuninter/index.php/meioAmbiente/article/view/397> TORRES SB, PAIVA EP, ALMEIDA JPN, BENEDITO CP, CARVALHO SMC. Teste de condutividade elétrica na avaliação da qualidade fisiológica de sementes de coentro. Revista Ciência Agronômica, 46(3): 622-629, 2015. 